\title{
A Study on the Use of Speech Acts: A Review of Selected Paper
}

\author{
Nofita Sari Gowasa ${ }^{1}$, Sonia Permata Radiana ${ }^{2}$, and Nur Afifah ${ }^{3}$ \\ ${ }^{1,2,3}$ U-Raise Academy, Pekanbaru, Indonesia \\ nofita.sg@unilak.ac.id
}

\begin{abstract}
ARTICLE HISTORY
Received : 11 April 2019

Revised : 21 April 2019

Accepted : 22 May 2019
\end{abstract}

\section{KEYWORDS}

Speech Act

Apology

Reject

Complain

Give Thanks

\begin{abstract}
This article is a review of the theory of speech act by Searle \& Austin (1962). Describe what the action strategies used in the language themselves are speaking and what speech acts are used by a group of prospective teachers while apologizing, complaining, rejecting and giving thanks. Focusing on the paper written by Akdeniz University, Faculty of Education Nihat Bayat, titled 'A study on the use of speech acts' (2013). This present paper uses descriptive qualitative analysis in an attempt to address the gap how to determine what type of speech act is used in the Turkish language strategy, which will provide convenience in teaching Turkish as a native and foreign language. Look at using data content analysis obtained from descriptive analysis for deeper processes. The data in this study were collected through asking participants to write the structure of the language they used in apologizing, complaining, rejecting and thanking. This present article aims to review and discuss the findings, as well as the strengths and weaknesses found in Bayat's paper. The article seems to have a clear flow on how to explain these two types of education and made the discourse easy to understand. Therefore, the replication of Bayat's research should be easy enough for similar research purposes.
\end{abstract}

\section{Introduction}

The act of speaking has been found in the language of communication. Speech act is a product of speech in certain conditions and the smallest of communication languages that determine the meaning of a sentence (Derin et al., 2019). Speech act is a pragmatic element that involves the speaker, listener or reader. In its application, speech acts are used by several disciplines. Speech act provisions arise because the speaker says something not only expresses the utterance, but also has the intention behind the utterance. At each opportunity, the action taken by producing speech will consist of three related actions, the first locutionary action, which is the basic act of speech, or produce meaningful language expression. The second is the act of illocution, the meaning of speech intended by the speaker. Third is perlocution act of action resulting from locution. In communicating with others can be done in various ways, one of which is done by speech.

Language plays an important role in human life because it is the main tool for communicating with each other. People use language to express thoughts, ideas and emotions by using sounds, movements and signals for various purposes and reasons. According to Clark (1977) language stands at the center of human affairs, from the most ordinary to the deepest. This means that language cannot be separated from everyday life. Everyone in the world when they use language in conversation, they produce speech in certain contexts. Speech is a speech analysis unit that has been defined in various ways but most commonly as a sequence of words in someone's turn to speak under a single intonation counter (Schmidt and Richards, 2002). This statement must be understood by the listener so that the speaker's message can be conveyed successfully. Therefore, it is necessary to know the context of the conversation. When language speakers produce speech in a particular context, they also take actions such as giving information, ordering, asking. Etc. This action is known as speech act. According to Searle and Austin (1962), there are three types of speech acts, namely locus acts, illocutionary acts, and acts of perlocution. The act of locution is the literal meaning of utterance. Meanwhile, illocutionary action refers to the extra meaning of utterance which is produced on the basis of its literal meaning and the act of perlocution is related to the effect of utterance on the listener, depending on certain circumstances. There are many functions of various types of speech acts such as exchanging factual information, intellectual information, emotional attitudes, moral attitudes, persuasion and socializing (Searle, 1976).

Speech action strategies such as what is used by a group of prospective teachers while apologizing, complaining, rejecting and giving thanks is tried to be defined in this study. in this case it focuses on the relationship between language and action, when using language people not only produce a series of isolated sentences, but also do an audit therefore by using language they do something or make others do something. The proper use of speech acts gained through experience in culture is very important in the realization of social relations. In some cases, to determine what type of speech act is used where the strategy in Turkish, will provide convenience in teaching Turkish as a 
native language and foreign language. Speech act, which is usually discussed in foreign language teaching research, is emphasized in that it reflects the usage problems faced by people from different cultures.

\section{Method}

The method used in this paper in this review article is descriptive qualitative, the data in this research article was collected through asking participants to write the structure of the language they used in apologizing, complaining, rejecting and thanking cases, participants were asked to write briefly their dialogue that they will take this speech act as a subject and the participants generally express acts of gratitude, apologize and reject explicitly, they mostly take action to complain implicitly. The data in the Bayat's study were taken from the participants of 155 teacher candidates who continued their education at Akdeniz University, the Faculty of Education, the Pre-School Teacher Education Department, and the participants were new students, second year students, and juniors in formal education. During the analysis of the data collected, 5 dialogues written by participants, because they did not adequately reflect the case needed, were found to be invalid and excluded from the study. Therefore, the number of study participants was determined 150 .

In Bayat's article several processes have been categorized and organized according to the strategies used in each speech act. From various categorization processes one will find more than one strategy in the structure of language, and consider what is most dominant which is presented by digitizing as frequency and percentage in the findings section. There are several functions considered in determining the strategy. For example, it has focused on what has been offered to do this action by the person who will apologize, and this has been properly named. The literature also benefits when identifying and mentioning strategies. But there are some functions and strategies not covered in the literature, onomathesias are determined by the agreement of experts analyzing the content used. Special attention is paid to the differences being significant between each strategy and the others. For example, although in the act of refusing, reminding other priority strategies is the strategy of giving reasons in a way where the importance is given higher importance causing this strategy to be called another word.

\section{Results \& Discussion}

\subsection{Strengths}

The authors say Bayat's article clearly describes the study of the use of speech acts and has a title that strongly reflects the content, and the title synchronized well with the abstract, which is written as a seemingly perfect summary of the entire research article of Bayat's. The keywords are appropriately narrowed, so it is easy to know what points are discussed in this study. In this paper to collect data through asking participants to write the structure of the language they use in apologizing, complaining, rejecting and thanking and the participants are asked to write their dialogue briefly that they will perform this speech act as a subject then the data is evaluated using content analysis techniques . Yildirim and Simsek (2011), emphasize that content analysis occurs by subjecting data obtained from descriptive analysis to deeper processes. So that with content analysis the author can quickly find out the results of using the speech act. And the findings of this article are very interesting and make people who read them better understand because the findings made in this research article are ten apologies, six rejections and six thank you strategies identified. While participants generally express acts of gratitude, apologize and reject explicitly, they mostly take action to complain implicitly. The implicit meaning according to Shapira-Lishchinsky (2019) is the meaning that is implied and not stated directly, not explicitly related to the information contained in a message and which is really intended by the speaker and understood by the listener, without being represented by anything in the discourse (Angelia, 2008). Implicit meaning is a meaning that is not displayed but is part of the speaker or the intention to be conveyed by the speaker. The meaning conveyed openly is explicit meaning.

In this article, appropriate use of speech acts gained through experience in culture is very important in the realization of social relations. Therefore, the use of speech act makes it much easier for people to understand and understand the intentions of others in speaking because it connects many aspects of life as in this article about culture in social relations not only in Turkey but throughout the world will be able to in the know about the importance of speech act in human life. The use of language and action relations is a very interesting thing discussed in this article. In this article the data collection uses content analysis in which the results can be known quickly by giving assignments to participants writing short memories about taking actions to apologize, complain, reject, and give thanks. Searle (2000) speech act is presented in situations where real language is used. Therefore, he said that the basic assumption on speech act theory is the smallest unit in human communication is the implementation of certain types of actions. Meanwhile, according to Bachman (1990), in communication cases are associated with the functional dimension of language. As opposed to the to morphological, syntactic and rhetorical dimensions regarding the arrangement of language structures, the pragmatic dimension is associated with producing and understanding speech. These two dimensions function reciprocally in communication.

There are differences related to speech acts according to Austin, namely constative and performative. Constative is used to describe an event or situation, is a statement. Constative can be qualified as true/false values. However, contstatives are used to perform tasks and cannot be categorized as true or false (Coulthard, 1985). Austin and 
Searle felt very interested in the show. Witczak-Plisiecka (2009) shows that three actions can occur simultaneously while making a statement. One of these is locutionary actions. This only explains the act of saying something. The act of illocution, on the other hand, is to do something by saying something. Perlocutionary actions are related to the conclusion of a word. This tells the effect that is left on the listener. Searle (2000) reviews this classification and makes several changes. Therefore, directives (ordering requests, prohibitions) aim at directing the listener to do something, declarations (resignations, appointments) that aim to make changes, commissives (promising) show that the speaker is doing something by expressing intention, expressive (apologizing), celebrating) expressing the speaker's state of mind in relation to a situation, firmly (Confessing, swearing) refers to the accuracy of what is said are the five types of speech acts carried out by Searleset The following conditions must be provided for formatives that do not function imperfectly: There must be a negotiation process that the impact of negotiations on this process is filled with the right words in the right circumstances by the right people. Conditions and people in certain situations must be the right conditions and people for the process. The process needs to be implemented correctly and fully by all participants (Coulthard, 1985). When performative expressions are carried out, the speaker does something simultaneously. For example, when it says It's very cold here, the speaker states he feels cold, or he can ask someone to close the window or turn on the heater. In addition, the speaker can perform ilucitionary actions by using lucitionary actions. Ask someone Can you give salt? It seems like it means that the listener has that ability; However, the speaker is actually making a request. This is an illusory act (Asher and Lascarides, 2006).

In this article examines social and culture in the use of a second language that uses 150 participants and participants write their memories about apologizing, complaining, rejecting and giving thanks. according to Hymes (1972) shows that when learning languages, children acquire a set of social rules in addition to grammatical structures. With this ability called communicative competence, the proper use of patterns is studied together with grammatical knowledge. In this way, knowledge of when to talk or not to speak, to whom, how, where and what to talk about is obtained. Others' speeches are evaluated in the same way. Hymes (1972) looked at the complementary relationship between communicative competence and language. The structure of the language obtained is precisely reflected in the case of communication through experience. In other words, language acquisition includes language rules and grammar structures along with their usage patterns. Children interpret life, they develop a general theory of forms of speech that are suitable. This assumption is suggested on an unlimited number of experiences with speech acts, and on the basis of their relationship to sociocultural features. The act of apologizing is one of the most frequently used actions. This has the purpose of tidying up hatred (Intachakra, 2004). Olshtain \& Cohen (1990) consider the act of complaining as an act of speech that is performed when the speaker is affected. Blum-Kulka and colleagues (1989) draw attention to the cultural specific dimensions of the act of refusing. As such, social distance and power differences between the parties have a significant impact on rejection. Meanwhile, according to Intachakra (2004), the act of gratitude rebuilds the balance difference that arises from the good that is created among which people communicate. Each of these actions is used with the aim of editing the social function of relationships through language.

In this article it is very clear in providing an explanation of data analysis and data collection, so it is very easy to find the results of the research. The results of the study in the article show that participants used different strategies depending on the type of performative. Variations in the strategy used are associated with specific conditions of communication and the quality of the parties involved in a communication. The research findings show that there are eight different strategies in the dimension of apology. Giving reasons, in particular, seems to be the most commonly used apology strategy. In the act of complaining, a total of ten strategies are determined. The strategies most frequently used include reflecting outcome strategies. Reflecting the results in the action of the complaint provides an implicit justification for the injured person to eliminate the emerging negativity. In the act of refusing, a total of six strategies are determined. The strategies most often used include giving reasons for the strategy. Giving a reason for that strategy is important compared to other strategies in terms of justifying a refusal to offer. Direct rejection, specifically refusing to use oaths and stating that there are no offers among other strategies, can be explained by the low level of respect between the communicating parties. The last speech act discussed in this study is a thank you. A total of six different strategies were determined in connection with thanks. Among these, giving thanks directly is the most often called strategy. Grateful has a strengthening function in the relationship because it shows that the parties acknowledge the goodness done and reflect the appropriate sensitivity. Grateful directly is often the strategy referred to can be linked to this.

\subsection{Weaknesses}

The advantages of Bayat's work, of course there are some weaknesses, namely, the research strategy of its discovery is similar to the data obtained from the research conducted in Korea. The abstract contained in the article did not state the purpose of the article, the introduction was lacking in elaboration. In the article the way to collect data is by participants writing their memories which are less effective in gathering data. Deficiencies in the article there is a relationship between various cases in the actions taken, the results found are not relevant to the research conducted. At this point, to determine which shows the strategies used in specific speech acts especially those collected are 
important findings of further learning. The research findings show that there are eight different strategies in the dimension of apology. Giving reasons, in particular, seems to be the most commonly used apology strategy. These results support the findings of a study conducted by Tuncel (2011). In his study, Tuncel (2011) did not face any consistent use in undergraduate speech act applications. The eight different apology strategies that were also achieved in this study are indirectly related to this finding. The strategy determined about the speech act of apology is similar to the data obtained from research conducted in Korean students learning English by Jung (2004). Expressions of apology that Jung (2004) found for these actions apologies and expressions of remorse, explanation and giving reasons, acknowledgment of responsibility and take responsibility, offer improvement, promise not to repeat and make commitments in this case studies are strategies that have a function that same. In the act of complaining, a total of ten strategies are determined. The strategy most often used among them reflect the results strategy. Reflecting the results in the action of the complaint provides an implicit justification for the injured person to eliminate the emerging negativity. Reflecting the results of a strategy that functions as an indirect expression, in some cases it can be treated as a gentle form of communication. Other strategies are used according to different variables in the communication process.

Some of the strategies obtained in this study (2010) are similar to the functions in the Deveci study (2010). The complaint strategy identified in a study of complaints in Turkey by Deveci (2010) is similar to the direct complaint in this study in terms of function. However, justification, candidate solutions, explanation of objectives and criticism found by Deveci (2010) are complaint strategies that were identified differently from this study. In the act of refusing, a total of six strategies are determined. The strategies most often used include giving reasons for the strategy. Giving a reason for that strategy is important compared to other strategies in terms of justifying a refusal to offer. Direct rejection, specifically refusing to use oaths and stating that there are no offers among other strategies, can be explained by the low level of respect between the communicating parties. However, refusing directly can be considered as one of the strategies implemented in some friendly relations, too. Al-Eryani (2007) focuses on three strategies in his studio. There are expressions of reasons for remorse and offer reasons for alternative strategies among these and give reasons in this study, alternative offers and other options have the same function as each other. Guo (2012), too, has focused on strategies such as direct, reason, alternative, avoidance and criticism. Among the strategies Guo (2012) identified, reasons, direct and alternative functions in the same way with some of the strategies in this study. The last speech act discussed in this study is a thank you. A total of six different strategies were determined in connection with thanks. Among these, giving thanks directly is the most often called strategy. Grateful has a strengthening function in the relationship because it shows that the parties acknowledge the goodness done and reflect the appropriate sensitivity. Grateful directly is often the strategy referred to can be linked to this. Other strategies used have the characteristics of linguistic expressions of expressing thanks more implicitly.

In his study, Intachakra (2004) also found a strategy, similar to the one in this study, related to acknowledgments in English and Thai. Explicit expressions of thanks and expressions of gratitude in this study, an account or a thank you and emphasize the positive impact, expression of admiration and praise, promise of repayment and disclosure of debt have the same function. Indications of no need for assistance are different findings determined by Intachakara (2004). Zarei (2011) obtained more strategies about thanking actions in her studies, and she divided them into sub-strategies. This is a sub-strategy of Zarei (2011) determined: gratitude, appreciation, payment, recognition of imposition, apology, positive feelings et al. Most of Zarei's (2011) strategies have the same function as the strategies determined in this study.

One response to be achieved in this study is related to the level of explicit or implicit use of speech acts. It was identified that the act of apology was carried out explicitly in terms of simplicity and implicit. It is generally stated explicitly this case is a reasonable case such as apologizing related to the fact that the speaker does not want mistakes to be made to damage the relationship. However, this is not the same case for complaining. The act of complaining is mainly implicit. The reason for this may be because the speaker complained under the risk of continuing relations with other parties. Therefore, such a risk-free way to thank is done very well explicitly. As for the act of refusing, it is carried out almost at the same level in a similar way in terms of simplicity and testimony. In this study, it aims to determine which strategies have been used when conducting speech acts. Other studies on speech acts generally relate to determining the extent and how foreign language students conduct them in the target language. However, finding strategies generally used in language must facilitate the interpretation of the results obtained from comparative studies. In his article discusses speech research but there is no data collection on speech in the article. The discovery of the article is not valid with the data collection.

\section{Conclusion}

The results of this study indicate that the participants used different strategies depending on the type of performative. Variations in the strategy used are associated with specific conditions of communication and the quality of the parties involved in a communication. The research findings show that there are eight different strategies in the dimension of apology. Giving reasons, in particular, seems to be the most commonly used apology strategy. The research findings show that there are eight different 
strategies in the dimension of apology. Giving reasons, in particular, seems to be the most commonly used apology strategy. In the act of complaining, a total of ten strategies are determined. The strategies most frequently used include reflecting outcome strategies. In the act of refusing, a total of six strategies are determined. The strategies most often used include giving reasons for the strategy. Giving a reason for that strategy is important compared to other strategies in terms of justifying a refusal to offer. Direct rejection, specifically refusing to use oaths and stating that there are no offers among other strategies, can be explained by the low level of respect between the communicating parties. However, rejecting directly can be considered as one of the strategies implemented in some friendly relations.

The last speech act discussed in this study is a thank you. A total of six different strategies were determined in connection with thanks. Among these, giving thanks directly is the most often called strategy. Grateful has a strengthening function in the relationship because it shows that the parties acknowledge the goodness done and reflect the appropriate sensitivity. Grateful directly is often the strategy referred to can be linked to this. Other strategies used have the characteristics of linguistic expressions of expressing thanks more implicitly. the response to be achieved in this study is related to the level of explicit or implicit use of speech acts. It was identified that the act of apology was carried out explicitly in terms of simplicity and implicit. It is generally stated explicitly this case is a reasonable case such as apologizing related to the fact that the speaker does not want mistakes to be made to damage the relationship. However, this is not the same case for complaining. The act of complaining is mainly implicit. The reason for this may be because the speaker complained under the risk of continuing relations with other parties. Therefore, such a risk-free way to thank is done very well explicitly. As for the act of refusing, it is carried out almost at the same level in a similar way in terms of simplicity and testimony. In this study, it aims to determine which strategies have been used when conducting speech acts. Other studies on speech acts generally relate to determining the extent and how foreign language students conduct them in the target language

\section{References}

Angelia, Y. S. (2008). A comparison of speech styles used in a radio station for young adults, Istara $F M$, and those used in a radio station for older adults, Delta FM (Doctoral dissertation, Petra Christian University).

Asher, N. \& Lascarides, A. (2006). Indirect speech acts. Synthese, 128 (1/2), 183-228. Retrieved from http://www.jstor.org/stable/20117151.

Austin, J. L. (1962). How to do things with words. Oxford: oxford university press.
Bachman, L. F. (1990). Fundamental considerations in language testing. Oxford: Oxford University Press.

Bayat, N. (2013). A study on the use of speech acts. Procedia-social and behavioral sciences, 70 , 213-221.

Blum-Kulka, S., House, J., \& Kasper, G. (1989). Investigating cross-cultural pragmatics: An introductory

Clark, C. 1997. Psychology and language: an introduction to psycholinguistics. New york: Oxford University Press.

Coulthard, M. (1985). An introduction to discourse analysis Applied linguistics and language study. New York: Longman.

Derin, T., Deliani, S., Fauziah, N., Afifah, N., \& Hamuddin, B. (2019). Indonesians' Tendency to Refer Abbreviation as Acronym: Types of Abbreviation as Word Formation Process. Globish: An EnglishIndonesian Journal for English, Education, and Culture, 8(2).

Deveci, T. (2010). The use of complaints in the interlanguage of Turkish EFL learners. (El uso de los reclamos en el inter-lengaje de estudiantes de ingles como lengua extranjera en Turquai). Colombian Applied Linguistics Journal, 12(2), 25-42.

Geurts, B. (2019). Communication as commitment sharing: speech acts, implicatures, common ground. Theoretical Linguistics, 45(1-2), 1-30.

Geurts, B. (2019). Communication as commitment sharing: speech acts, implicatures, common ground. Theoretical Linguistics, 45(1-2), 1-30.

Guo, Y. (2012). Chinese and American refusal strategy: A cross-cultural approach. Theory and Practice in Language Studies, 2(2), 247.

Hymes, D. (1972). On communicative competence. In D. Hymes, J.B. Pride, \& J. Holmes. (Eds.), On

Intachakra, S. (2004). Contrastive pragmatics and language teaching: Apologies and thanks in English and Thai. RELC Journal: A Journal of Language Teaching and Research, 35(1), 37-62.

Jung, E. H. S. (2004). Interlanguage pragmatics: Apology speech acts. In Carol Lyan Moder \& Aida

Marquez, R. R. (2000). Linguistic politeness in Britian and Uruguay; A contrastive study of requests and apologies. Philadelphia: John Benjamins Publishing Company.

Olshtain, E., \& Cohen, A. (1990). The learning of complex speech act behaviour. TESL Canada journal, 45-65.

Petrey, S. (2016). Speech acts and literary theory. Routledge. 
Richards, Jack C and Richard Schmidt. 2002. Longman dictionary of language teaching and applied linguistics, 3rd Ed., London: Pearson Education Limited

Rosyidi, A. Z., Mahyuni, M., \& Muhaimi, M. (2019). Illocutionary Speech Acts Use by Jokowidodo in First Indonesia Presidential Election Debate 2019. International Journal of Multicultural and Multireligious Understanding, 6(2), 735-740.

Searle, J. R. (2000). Soz edimleri. (R. Levent Aysever, Trans.)

Searle, J. R. 1969. Speech Acts. Cambridege University Press.

Shapira-Lishchinsky, O. (2019). The implicit meaning of TIMSS: Exploring ethics in teachers' practice. Teaching and Teacher Education, 79, 188197.

Witczak-Plisiecka, I. (2009). Speech acts and the autonomy of linguistic pragmatics. Lodz Papers in Pragmatics, 5(1), 85-106.

Wittgenstein, Ludwig 1953 Philosophical Investigations, trans, by G.E.M. Anscombe. Oxford: Basil Blackwell

Yamori, K. (2019). Disaster Information from the Viewpoint of Speech Act Theory. IDRiM Journal, 9(1), 40-55.

Yandra, A., Safitri, D., \& Hamuddin, B. (2018, July). Exploring Discourse of Illocutionary Act: The Controversial Pribumi Anies Baswedan's Speech. In IOP Conference Series: Earth and Environmental Science (Vol. 175, No. 1, p. 012230). IOP Publishing. 